\title{
Cellular Imaging of zif268 Expression in the Hippocampus and Amygdala during Contextual and Cued Fear Memory Retrieval: Selective Activation of Hippocampal CA1 Neurons during the Recall of Contextual Memories
}

\author{
Jeremy Hall, Kerrie L. Thomas, and Barry J. Everitt \\ Department of Experimental Psychology, University of Cambridge, Cambridge, CB2 3EB United Kingdom
}

\begin{abstract}
The neuroanatomical and molecular basis of fear memory retrieval was studied by analyzing the expression of the plasticityassociated immediate early gene zif268. Cellular quantitative in situ hybridization revealed that zif268 is expressed within specific regions of the hippocampus and amygdala during fear memory retrieval. Within the hippocampus, increased expression of zif268 was observed within CA1 neurons, but not dentate gyrus neurons, during the retrieval of contextual, but not cued, fear associations. In contrast, zif268 expression was increased within neurons of the amygdala (lateral, basal, and central nuclei) during the retrieval of both contextual and cued fear memories. These results demonstrate activation of hippocampal CA1 neurons in contextual fear memory retrieval that
\end{abstract}

was not merely a correlate of the behavioral expression of fear itself, because it was limited to the retrieval of contextual, and not cued, fear memories. Further studies revealed that the selective increase in hippocampal CA1 zif268 expression seen after contextual fear memory retrieval was limited to the retrieval of recent $(24 \mathrm{hr})$ but not older $(28 \mathrm{~d})$ memories. These experiments represent the first demonstration that zif268 expression in specific neuronal populations is associated with memory retrieval and suggest that this gene may contribute to plasticity and reconsolidation accompanying the retrieval process.

Key words: zif268; gene expression; fear conditioning; memory retrieval; hippocampus; amygdala
The hippocampus and amygdala form part of a neural system required for fear memory (Selden et al., 1991; Aggleton, 1992; Davis, 1992; Phillips and LeDoux, 1992; Rogan and LeDoux, 1996; Fendt and Fanselow, 1999; Hamann et al., 1999). A widely held view is that the hippocampus is required for the formation and retrieval of context-fear associations, whereas the amygdala is required for conditioning and recall of associations to contextual and discrete cues (Maren and Fanselow, 1996; Rogan and LeDoux, 1996). Recent investigations have revealed that fear memory recall induces a reconsolidation of memories requiring new protein synthesis (Nader et al., 2000). Significant questions, however, remain concerning both the neuroanatomical and molecular substrates of fear memory retrieval.

First, several studies have questioned the involvement of the hippocampus in the retrieval of aversive associations (Gewirtz et al., 2000). Lesions of the hippocampus disrupt contextual fear memory retrieval when measured by conditioned freezing (Kim and Fanselow, 1992; Maren et al., 1997; Fanselow, 2000), but not necessarily when assessed by other behavioral measures ( $\mathrm{McNish}$ et al., 1997; Gisquet-Verrier et al., 1999; Gewirtz et al., 2000). Furthermore, whereas some studies of post-training hippocampal lesions suggest a time-limited role for the hippocampus in fear memory retrieval (Kim and Fanselow, 1992; Anagnostaras et al.,

Received Nov. 8, 2000; revised Dec. 20, 2000; accepted Jan. 5, 2001.

This work was supported by a Medical Research Council (MRC) Program Grant G9537855 and an MRC Cooperative in Brain, Behavior, and Neuropsychiatry. J.H. was supported by Trinity College (Cambridge, UK) under the Cambridge Clinical School $\mathrm{MB} / \mathrm{PhD}$ program. We thank Trevor Robbins for helpful discussions and Caroline Morrison for technical assistance.

Correspondence should be addressed to Dr. Kerrie L. Thomas, Department of Experimental Psychology, University of Cambridge, Downing Street, Cambridge, CB2 3EB UK. E-mail: klt25@cus.cam.ac.uk.

Copyright (C) 2001 Society for Neuroscience $0270-6474 / 01 / 212186-08 \$ 15.00 / 0$
1999), other reports have suggested that the amnesic effect of hippocampal lesions may extend to older memories (Nadel and Moscovitch, 1997).

Second, although the amygdala plays a critical role in fear memory retrieval (Liang et al., 1982; Kim and Davis, 1993; Lee et al., 1996; Maren et al., 1996; Muller et al., 1997), the exact nature of its involvement remains controversial. Some authors have argued that the basolateral amygdala (BLA) is the central locus of all fear conditioning (Fanselow and LeDoux, 1999). However, certain forms of discrete and contextual fear conditioning persist despite lesions to the BLA (Selden et al., 1991; Killcross et al., 1997; Vazdarjanova and McGaugh, 1998; Cahill et al., 1999; Maren, 1999), reflecting either the involvement of other amygdaloid nuclei in fear memory recall (Killcross et al., 1997) or a more limited involvement of the amygdala in the acquisition, but not the storage, of fear memories (McGaugh et al., 1996; Cahill and McGaugh, 1998).

Finally, little is known about the molecular events underlying synaptic plasticity accompanying fear memory retrieval. A role for protein synthesis in memory reconsolidation at retrieval has been demonstrated (Nader et al., 2000), however, the specific genes involved have yet to be identified. One candidate is the immediate early gene (IEG) zif268 (or EGR-1, krox-24, TIS-8). The expression of zif 268 has been closely correlated with the induction of hippocampal long-term potentiation (LTP) (Cole et al., 1989; Wisden et al., 1990; Worley et al., 1993), a major form of protein synthesis-dependent plasticity in the adult brain, as well as the predominant cellular model of learning (Bliss and Collingridge, 1993). The involvement of zif268 in memory retrieval has not previously been investigated.

In the present study we demonstrate that expression of zif 268 
accompanies Pavlovian fear memory retrieval, and we use the quantification of zif268 expression to define differential regional activation within the hippocampus and amygdala during the retrieval of both cued and contextual fear associations. This approach using cellular imaging may help to resolve discrepancies in the literature concerning the involvement of the amygdala and hippocampus in fear memory after its acquisition.

\section{MATERIALS AND METHODS}

Animals. A total of 82 male hooded Lister rats (Olac, Bicester, UK) weighing between 280 and $320 \mathrm{gm}$ were used. The animals were housed in pairs and kept in a holding room at $21^{\circ} \mathrm{C}$ under reverse light conditions (lights off at 8:30 A.M.). Animals were allowed ad libitum access to food and water and were handled on 3 consecutive days for $1 \mathrm{~min}$ before the experiments.

Cued and contextual fear conditioning and retrieval. Animals were differentially conditioned to associate either an auditory cue or an experimental context with a footshock using a novel version of the conditioned freezing procedure. Animals were first pre-exposed for $3 \mathrm{~d}$ to two experimental chambers (contexts) for $20 \mathrm{~min} / \mathrm{d}$. These contexts were designed to differ in a number of features including size, spatial location, odor, and lighting. In addition, to further the distinguish the contexts, each animal was only exposed to each chamber at a distinct time of day. After this pre-exposure period rats were given one $25 \mathrm{~min}$ training trial in one of the environments to associate either a discrete $10 \mathrm{sec}$ cue $[4 \mathrm{~Hz}, 80 \mathrm{~dB}$ clicker, the conditioned stimulus (CS)] or the experimental context itself with a footshock $[0.5 \mathrm{sec}, 0.45 \mathrm{~mA}$ shock, the unconditioned stimulus (US)]. Animals in the cued training condition received five cue presentations (interstimulus interval $5 \pm 1$ min) that terminated in the delivery of the footshock (cued group), whereas animals in the contextual training condition received an equivalent number of CS and US presentations in pseudorandom order (context group). Freezing behavior served as a measure of conditioned fear to the discrete cue at a retrieval test $48 \mathrm{hr}$ after conditioning in which the rats were placed in the nontraining context and exposed to an $8 \mathrm{~min}$ presentation of the clicker cue. The next day all the rats were tested for conditioning to contextual stimuli, as assessed by conditioned freezing during an 8 min retrieval test in the training context. Freezing behavior was video-recorded and quantified by an observer blind to the experimental group. One unit of freezing was defined as a continuous absence of movement other than that required for respiration for $5 \mathrm{sec}$, and behavior was expressed as a percentage of units spent freezing.

For in situ hybridization experiments, animals in the cued and context training groups were trained as described above and killed 30 min after exposure to either the conditioned context (first experiment) or auditory cue (second experiment) $3 \mathrm{~d}$ after conditioning. Two additional control groups were also included in the in situ hybridization experiments. The first of these (control group) received shock training as described but were killed without testing $3 \mathrm{~d}$ after training. The second, box group, were trained, tested, and killed with the cue and context groups, but received neither footshock nor cue presentations.

Retrieval of old versus recent fear associations. Animals were randomly allocated to two experimental groups: control and conditioned. All animals were extensively handled before the onset of the experiment. On the first experimental day (training day) rats from the control and conditioned groups were placed individually in the training box for 10 min. During this time animals in the conditioned group but not in the control group received $5 \times 1 \mathrm{sec} 0.45 \mathrm{~mA}$ footshocks spaced pseudorandomly across the 10 min session. In all cases the first shock presentation occurred at least $1 \mathrm{~min}$ after the introduction of the rats to the chamber. Rats in the control group were allowed to explore the novel context for 10 min without receiving any stimulus presentations. All rats were returned to their home cages after training.

On the retrieval testing day, either $24 \mathrm{hr}$ or $28 \mathrm{~d}$ after training, both groups of rats were returned to the training box for 8 min, during which time their behavior was recorded on video. These videos were later screened for freezing behavior as described above. For in situ hybridization experiments, rats were killed 30 min after testing.

Tissue preparation. Rats were killed by $\mathrm{CO}_{2}$ exposure and decapitation $30 \mathrm{~min}$ after the end of behavioral testing, and whole brains were rapidly removed and frozen on dry ice. The brains were stored at $-70^{\circ} \mathrm{C}$ until sectioned. Sections $(14 \mu \mathrm{m})$ were cut at $-20^{\circ} \mathrm{C}$ on a freezing microtome (Leica, Nussloch, Germany) and thaw-mounted onto poly-L-lysine (hydrobromide; molecular mass >300,000; Sigma, Poole, UK)-coated glass slides $(0.02 \mathrm{mg} / \mathrm{ml}$ diethyl pyrocarbonate-treated water $)$. The sections were air-dried for not $<30 \mathrm{~min}$, fixed in $4 \%$ paraformaldehyde in $0.1 \mathrm{M}$

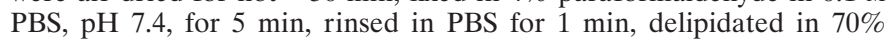
ethanol for $4 \mathrm{~min}$, and stored in $95 \%$ ethanol at $4^{\circ} \mathrm{C}$.

In situ hybridization. A cDNA antisense probe complementary to nucleotides 460-505 of the zif268 gene (Milbrandt, 1987) was synthesized on an Applied Biosystems (Foster City, CA) DNA Synthesizer. This oligonucleotide was $3^{\prime}$ end-labeled with $\left[\alpha^{-}{ }^{35}\right.$ S $]$ dATP $(1200 \mathrm{Ci} / \mathrm{mmol}$; NEN, Hounslow, UK) in a 30:1 molar ratio of radiolabeled ATP:oligonucleotide using terminal deoxynucleotidyl transferase (Promega, Southampton, UK) as described previously (Wisden and Morris, 1994). Specific activity of the ${ }^{35} \mathrm{~S}$-labeled probe was between $2.0 \times 10^{5}$ and $8.0 \times 10^{5} \mathrm{dpm} / \mu 1$ probe.

Hybridizations were performed essentially as described by Wisden and Morris (1994). To define nonspecific hybridization, adjacent slidemounted sections were incubated with radiolabeled oligonucleotide in the presence of an excess $(100 \times)$ concentration of unlabeled oligonucleotide probe. After hybridization sections were opposed to Eastman Kodak (Rochester, NY) BioMax x-ray film for 1-2 weeks. After obtaining appropriate $\mathrm{x}$-ray film exposures, sections were dipped in $\mathrm{K} 5$ photographic emulsion (Ilford). Sections were exposed for 5-10 weeks at $4^{\circ} \mathrm{C}$, before development and counterstaining with $0.01 \%$ thionin.

Silver grain density was assessed in discrete neuronal populations using OpenLab imaging software (ImproVision Coventry, UK) [CA1 pyramidal neurons and dentate gyrus (DG) granule cells, bregma $-3.3 \mathrm{~mm}$; basal amygdala (B) neurons, bregma $-3.0 \mathrm{~mm}$; lateral amygdala (LA) neurons, bregma $-3.0 \mathrm{~mm}$; accessory basal nucleus of the amygdala (AB) neurons, bregma $-3.5 \mathrm{~mm}$, and central nucleus of the amygdala $(\mathrm{CeN})$ neurons, bregma $-2.0 \mathrm{~mm}$. Grains (total and nonspecific) were counted over sufficient randomly selected neurons from each region for each animal such that the SE of the counts for any region was $<10 \%$ of the population mean (typically 20 cells). In each case cells were selected from at least three separate sections. A specific grain count was then calculated for each region by subtracting total and nonspecific counts. The mean silver grain count in each region for each animal was then divided by the mean count in that region for the control group to give a standardized grain count for each group. Standardized results were analyzed by ANOVA, and individual post hoc comparisons were made using Sidak's test (corrected pairwise comparisons).

\section{RESULTS}

\section{Differential Pavlovian fear conditioning to discrete or contextual stimuli}

Conditioning of the cued and context groups to the CS (discrete auditory cue) and to the experimental context as measured by conditioned freezing during the retrieval tests is shown in Figure 1. Analysis of the total amount of freezing in each group (cued or context) by ANOVA revealed a group $\times$ stimulus interaction $\left(F_{(1,18)}=100.2 ; p<0.001\right)$. This effect was characterized by greater freezing to the discrete CS in the cued group compared with context group $\left(F_{(1,18)}=129.0 ; p<0.001\right)$, and greater freezing to the contextual cues in the context group compared with the cued group $\left(F_{(1,18)}=8.2 ; p=0.01\right)$. Thus, animals in the cued and context groups, despite receiving the same total number of stimulus presentations, showed a double dissociation in their conditioning to the CS and the context, respectively.

\section{Expression of zif268 after the retrieval of contextual fear associations}

We used in situ hybridization to investigate whether the plasticity-associated IEG zif268 is expressed in neurons of the hippocampus and amygdala after the retrieval of contextual fear associations. Animals were trained in the cued, context, box, and control conditions described above and were killed 30 min after testing of retrieval responses to the context. There was a significant effect of group on freezing behavior $\left(F_{(2,15)}=\right.$ 9.6; $p<0.01)$ derived from a greater level of freezing in the 


\section{Freezing to Discrete and Contextual Cues}

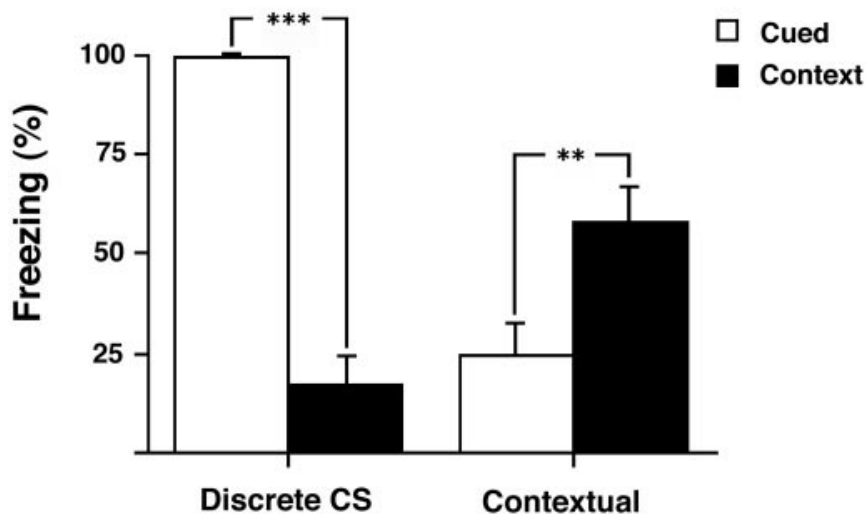

Figure 1. Freezing in response to presentation of discrete or contextually conditioned cues. Freezing (percentage $8 \mathrm{~min}$ after cue) in response to presentation of discrete CS (clicker) and contextual cues in rats trained with either clicker-shock pairings (cued; $n=10$ ) or pseudorandom presentations of clicker and shock (context; $n=10$ ). There was greater freezing to the discrete CS in the cued compared with context group and greater freezing to the contextual cues in the context compared with cued group. All results are presented as mean \pm SEM values.

context group than in either the cued $(p<0.05)$ or box $(p<$ 0.01 ) groups (Fig. 2a). Analysis of the expression of zif268 in hippocampal CA1 neurons and in the DG after the context retrieval test revealed an effect of group on zif 268 expression in CA1 $\left(F_{(3,20)}=21.8 ; p<0.001\right)$ but not in the DG $\left(F_{(3,20)}=2.0\right.$; $p=\mathrm{NS}$ ) (Fig. 2b-e). The effect of group on zif268 expression in CA1 was shown by post hoc tests to derive from a higher level of expression of zif268 in the context group than in either the cued ( $p<0.01)$, box $(p<0.001)$, or control $(p<0.001)$ groups. In addition the cued group, although expressing significantly less zif268 in CA1 than the context group, also showed increased expression relative to the control group ( $p<$ $0.01)$. No differences in zif268 expression were seen between the box and control groups.

There was also increased zif268 expression in several nuclei of the amygdala in the context group. Analysis demonstrated a significant effect of group on zif268 expression in neurons in the $\mathrm{B}\left(F_{(3,20)}=9.5 ; p<0.001\right), \operatorname{LA}\left(F_{(3,20)}=8.0 ; p=0.001\right)$, and $\mathrm{CeN}\left(F_{(3,20)}=17.9 ; p<0.001\right)$, but not the $\mathrm{AB}\left(F_{(3,20)}=\right.$ $2.8 ; p=\mathrm{NS})$. Further post hoc comparisons confirmed that the significant effect of group in the B, LA, and $\mathrm{CeN}$ was attributable to increased zif268 expression in the context group relative to cued, box, and control groups in the $\mathrm{B}$ and $\mathrm{CeN}$ and in the context group relative to the cued and control groups in the LA (Fig. $2 f-i$ ).

In summary these results show that animals from the context group showed significantly greater contextual conditioning, as assessed by conditioned freezing, than animals from the cued or box training conditions. In response to the context retrieval test a large increase in zif268 expression was seen in CA1 but not in the DG of animals from the context group, and this increase was greater than that seen in the cued group. In addition, animals in the context group, but not in the cued group, showed higher levels of zif268 expression in the B, LA, and $\mathrm{CeN}$ nuclei of the amygdala than control animals when exposed to a fear-conditioned context.

\section{Freezing to Contextual Cues}

\section{Zif268 Expression}
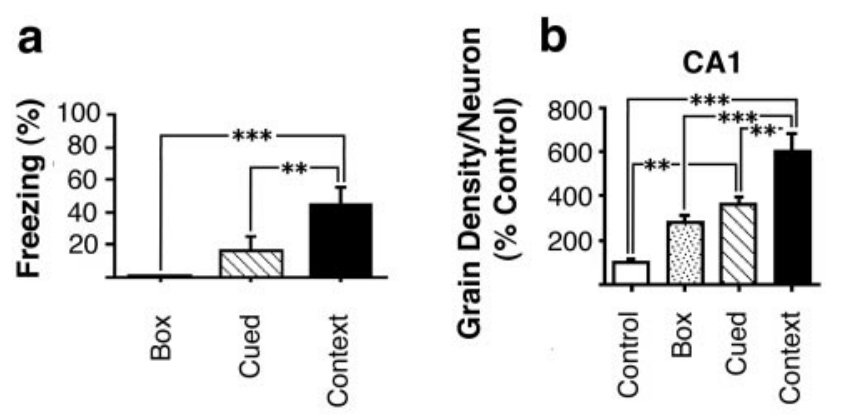

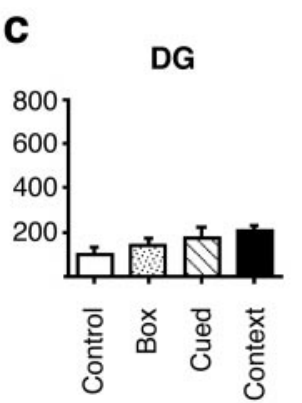

d

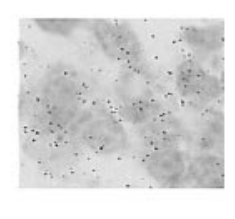

Control CA1
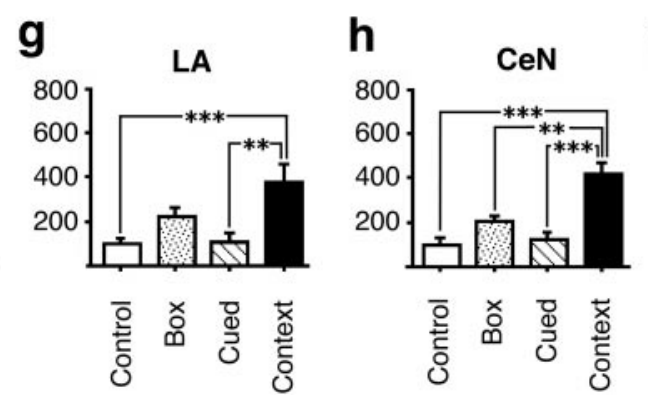

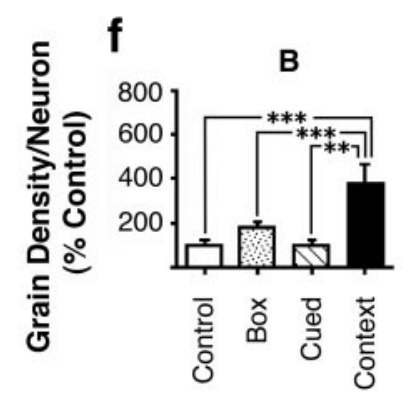

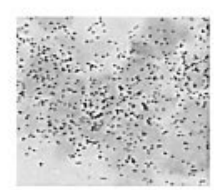

Context CA1

Figure 2. Expression of zif268 after the retrieval of contextual fear associations. $a$, Freezing of rats in the box (exposure to context only during training and testing; $n=6)$, cued $(n=6)$, and context $(n=6)$ groups in response to re-exposure to contextual stimuli at the retrieval test. Animals in the control group $(n=6)$ were given shock and cue presentations on the training day but were not tested later. $b-i$, Zif268 expression 30 min after re-exposure to contextual stimuli. $b, c$, Zif268 expression in neurons in the hippocampus: CA1 $(b)$, DG $(c)$. $d$, $e$, Photomicrographs $(100 \times)$ of small dark silver grains associated with CA1 pyramidal cells from an individual rat from the control $(d)$ and context $(e)$ groups. $f$, $i$, Zif268 expression in neurons in the amygdala: $\mathrm{B}(f), \mathrm{LA}(g), \mathrm{CeN}(h)$, and $\mathrm{AB}(i)$. All results are presented as mean $\pm \mathrm{SEM}$ values. 


\section{Freezing to a Discrete Cue}
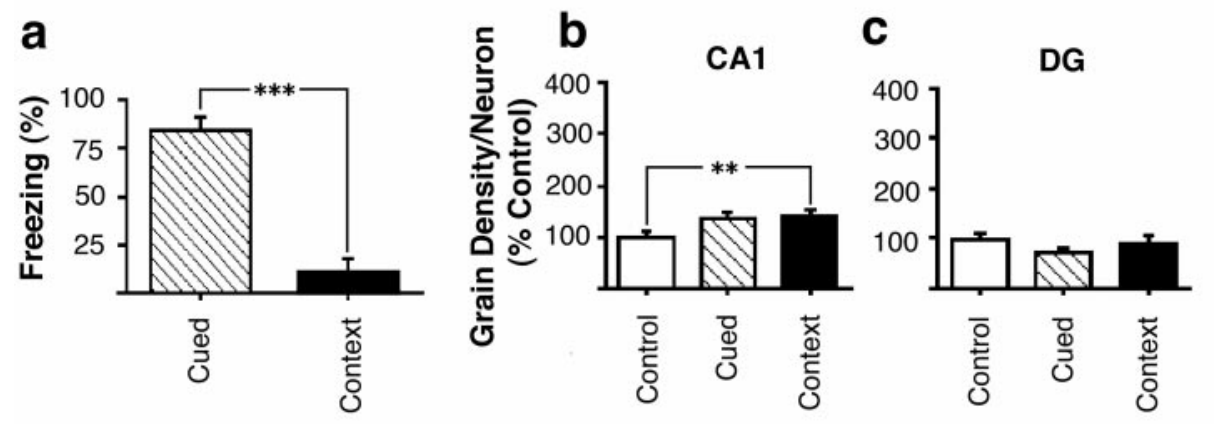

d
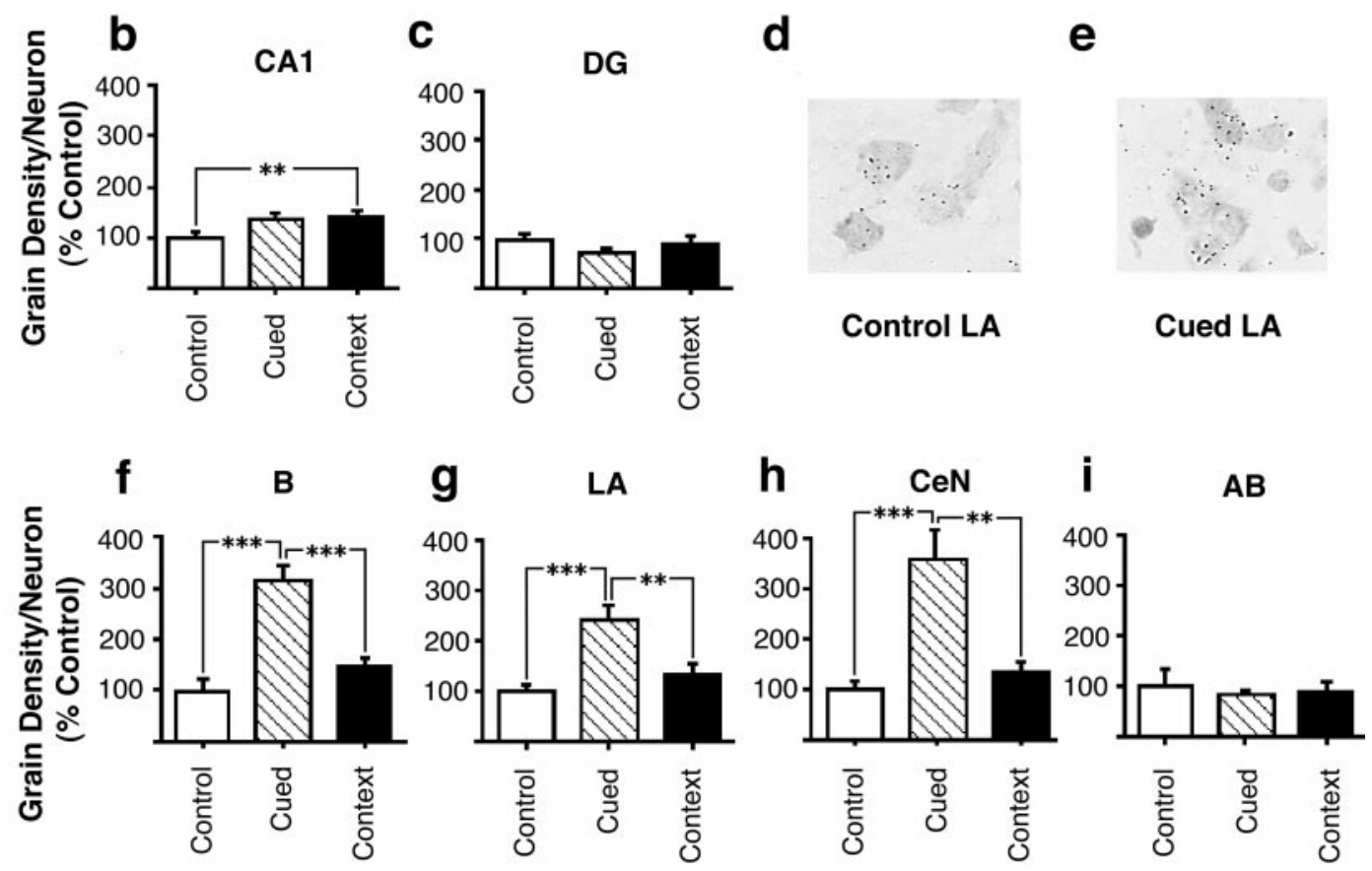

Figure 3. Expression of zif268 after the retrieval of discrete CS fear associations. $a$, Freezing of rats in the cued $(n=8)$ and context $(n=8)$ groups in response to re-exposure to the discrete cue at retrieval testing. Animals in the control group $(n=8)$ were given shock and cue presentations on the training day but were not tested later. $b-i$, Zif268 expression $30 \mathrm{~min}$ after re-exposure to the cue stimulus stimuli. $b, c$, Zif268 expression in neurons in the hippocampus: CA1 $(b), \mathrm{DG}(c) . d$, $e$, Photomicrographs $(100 \times)$ of small dark silver grains associated with LA pyramidal cells from an individual rat from the control $(d)$ and cued $(e)$ groups. $f, i$, Zif268 expression in neurons in the amygdala: B $(f), \mathrm{LA}(g), \mathrm{CeN}(h)$, and AB $(i)$. All results are presented as mean \pm SEM values.

\section{Expression of zif268 after the retrieval of cued fear associations}

We next investigated the expression of zif268 in the hippocampus and amygdala during the retrieval of a cued, rather than contextual, fear association. This allowed us to investigate whether a common system is recruited during the retrieval of fear-related memories or if instead certain structures are selectively required for the retrieval of cued or contextual associations.

Animals were trained in the cued and context groups described above and were killed $30 \mathrm{~min}$ after testing of retrieval responses to the CS. Because no differences were observed between the control and box groups in the previous experiment, only a single control group was used in the second experiment (control condition).

The freezing responses of animals from the cued and context groups during the CS retrieval test are shown in Figure $3 a$. Analysis of the time spent freezing during the CS presentation revealed a significant effect of group $\left(F_{(1,14)}=51.7 ; p<0.001\right)$ resulting from a greater freezing response to the CS in the cued group than in the context group.

Analysis of zif268 expression in the hippocampus of animals retrieving the cued fear association revealed a different pattern from that seen after the retrieval of a contextual fear association. There was a significant overall effect of group on zif268 expression in pyramidal neurons in the CA1 $\left(F_{(2,21)}=4.5 ; p<0.05\right)$ (Fig. $3 b)$. Post hoc tests revealed that there was a significant increase in CA1 zif268 expression in the context group relative to the control group. However, because there were no differences in zif268 expression between the cued and control $(p>0.07)$ or between the cued and context groups $(p>0.9)$, the increase over basal expression of zif268 in the context group was not related to conditioning to the discrete cue. There was no effect of group on zif268 expression within the DG $\left(F_{(2,21)}=1.35 ; p=\right.$ NS; Fig. $\left.3 c\right)$.

In contrast, zif 268 expression in the amygdala of animals retrieving a cued fear association showed a similar pattern to that seen after the retrieval of a contextual fear association. Thus, there was a significant effect of group on zif268 expression in neurons in the B $\left(F_{(2,21)}=29.7 ; p<0.001\right)$, LA $\left(F_{(2,21)}=11.5\right.$; $p<0.001)$, and $\mathrm{CeN}\left(F_{(2,21)}=14.9 ; p<0.001\right)$, but not in the AB $\left(F_{(2,21)}=0.2 ; p=\mathrm{NS}\right)$. Furthermore post hoc analysis revealed that the significant effect of group on zif268 expression within the $\mathrm{B}, \mathrm{LA}$, and $\mathrm{CeN}$ derived in all cases from increased expression in the conditioned (cued) group relative to the context and control groups (Fig. 3d-i).

In summary therefore, rats from the cued group showed selective conditioning to the CS compared with the animals in the context group, as shown by their freezing response during CS presentation in the cued retrieval test. Retrieval of a discrete fear association however produced no difference between the cued and context groups in terms of zif 268 expression in the CA1 pyramidal neurons of the hippocampus. However, retrieval of the cued fear association did selectively increase zif268 expression in the cued group in the $\mathrm{B}, \mathrm{LA}$, and $\mathrm{CeN}$, but not the $\mathrm{AB}$, of the amygdala. This pattern of zif 268 activation within the amygdala was therefore common to the retrieval of both cued and contextual fear associations. 


\section{Hours}

Freezing (\%)
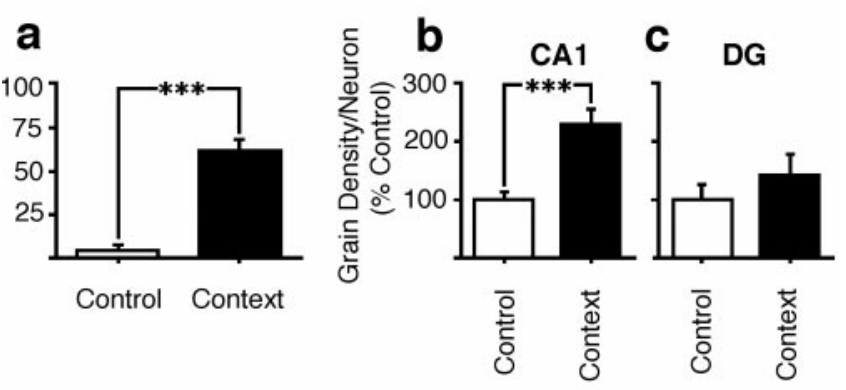

28 Days
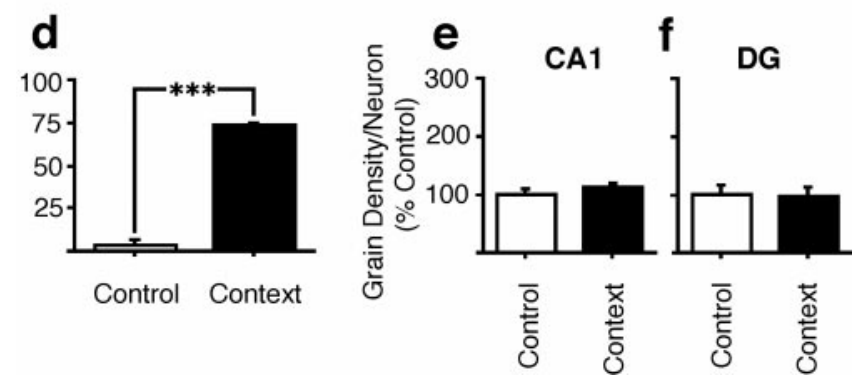

Figure 4. Expression of zif 268 after the retrieval of recent versus old contextual-fear associations. $a$, Freezing of rats in the control and context groups in response to re-exposure to training context $24 \mathrm{hr}$ after training. Expression of zif268 in neurons of the CA1 (b) and DG (c) after memory retrieval at 24 hr. $d$, Freezing of rats in the control and context groups in response to re-exposure to training context $28 \mathrm{~d}$ after training. Expression of zif268 in neurons of the CA1 $(e)$ and DG $(f)$ after memory retrieval at $28 \mathrm{~d}$. All results are presented as mean \pm SEM values.

\section{Hippocampal zif268 expression during the retrieval of recent versus old contextual fear associations}

The previous experiments demonstrated a selective activation of zif268 expression in CA1 after contextual memory retrieval, which was hence a consequence of contextual memory retrieval itself rather than the expression of fear. We therefore further investigated the activation of the hippocampal CA1 neurons during memory retrieval by comparing zif268 expression in the hippocampus of animals retrieving either recent ( $24 \mathrm{hr})$ or old (28 d) contextual fear associations.

In a first experiment zif268 expression in the hippocampus was measured after the retrieval of a contextual fear association acquired 24 hr previously. Contextual fear responding measured at retrieval testing confirmed significantly greater conditioned freezing in the conditioned than in the control group $\left(F_{(1,10)}=\right.$ 56.9; $p<0.001)$. Analysis of zif268 expression within CA1 by ANOVA also revealed a significant increase in zif 268 expression in animals in the conditioned group relative to the control group after the $24 \mathrm{hr}$ retrieval test $\left(F_{(1,10)}=24.2 ; p=0.001\right.$; Fig. $\left.4 b\right)$. In contrast, there was no effect of retrieval on expression in the DG $\left(F_{(1,10)}=0.9 ; p=\right.$ NS; Fig. $\left.4 c\right)$. These results therefore confirmed our earlier finding of CA1 zif268 expression during contextual fear memory retrieval using a second contextual conditioning procedure.

We next sought to confirm that the expression of zif268 in the CA1 region after the $24 \mathrm{hr}$ retrieval test was not a residual effect of the conditioning procedure itself. Rats from the control and context groups were killed $24 \mathrm{hr}$ after training directly from their home cages without testing retrieval. Analysis of the results of in situ hybridization for zif268 mRNA in the hippocampi of these rats showed that there was no difference between the groups in the expression of zif268 in CA1 [grain density (\% control) \pm SEM: control group, $1.00 \pm 0.09$; context group, $1.14 \pm 0.15$, $\left.F_{(1,10)}=0.08, p>0.78\right]$.

Finally, we investigated the expression of zif268 in the hippocampus of animals retrieving older (28 d) contextual fear associations. Animals in the context group still showed robust retrieval of the contextual fear association at this time point, as confirmed by a significant effect of group on conditioned freezing during the retrieval test $\left(F_{(1,10)}=73.3, p<0.001\right.$; Fig. $\left.4 d\right)$. Furthermore, there was no decrease in conditioned freezing during retrieval at $28 \mathrm{~d}$ compared with $24 \mathrm{hr}$ (freezing scores, $24 \mathrm{hr}$, $60.6+7.2 \% ; 28 \mathrm{~d} 73.9+1.3 \%$ ). However, after retrieval at $28 \mathrm{~d}$ there was no difference in zif268 expression between the context conditioned and control groups in CA1 $\left(F_{(1,10)}=1.2 ; p=\mathrm{NS}\right.$; Fig. $4 e$ ), in contrast to the effect seen at $24 \mathrm{hr}$. There was also no difference between groups in terms of zif 268 expression within the DG at this time point $\left(F_{(1,10)}=0.05 ; p=\right.$ NS; Fig. $\left.4 f\right)$.

In summary, the results of these experiments show that rats aversively conditioned to a novel context showed increased expression of zif 268 mRNA in CA1 after the retrieval of the contextual association $24 \mathrm{hr}$, but not $28 \mathrm{~d}$, after training. No changes in zif268 expression were seen at either time point in the DG.

\section{DISCUSSION}

In the present study we have shown that the plasticity associated IEG zif268 is expressed in specific regions of the hippocampus and amygdala during the retrieval of fear-related memories. Training was conducted using a procedure in which rats were differentially conditioned to either cued or contextual stimuli, despite receiving the same total number of stimulus presentations, by altering the contingency between the CS and US, thereby providing a rigorous control for stimulus exposure. Expression of zif 268 in the $\mathrm{B}, \mathrm{LA}$, and $\mathrm{CeN}$ of the amygdala accompanied the retrieval of both contextual and cued fear associations, indicating a role for these nuclei in the retrieval of fear-related memories. However, expression of zif 268 in the CA1 region of the hippocampus was selectively increased during the retrieval of contextual, but not cued, fear-related memories. Hippocampal CA1 zif268 expression was therefore specifically related to contextual memory retrieval and could not be explained as a more general correlate of the production of a fear-related response. Further investigation of the time course of CA1 zif268 expression during fear memory retrieval revealed a selective increase during the recall of recent ( $24 \mathrm{hr}$ ), but not old (28 d) contextual memories, supporting a time-limited role of hippocampal CA1 neurons in memory consolidation and retrieval.

\section{Hippocampal zif268 expression during the retrieval of contextual fear memories}

The specific activation of CA1 neurons during the retrieval of contextual, but not cued, fear associations provides strong evidence for a mnemonic role of the hippocampus in the recall of contextual information and complements the results of studies of hippocampal lesions (Selden et al., 1991; Phillips and LeDoux, 1992; Kim and Fanselow 1992) and reversible inactivation of the hippocampus (Bellgowan and Helmstetter, 1995; Holt and Maren, 1999). This contrasts with suggestions that deficits in contextual freezing seen in animals with hippocampal lesions 
derive solely from lesion-induced locomotor hyperactivity (Good and Honey 1997; McNish et al., 1997; but see Maren et al., 1998), and provides strong support for an involvement of the hippocampus in this form of conditioning. However, as some studies have demonstrated different forms of contextual fear conditioning in hippocampal lesioned subjects, it remains possible that not all forms of contextual conditioning require hippocampal integrity (Gewirtz et al., 2000).

One key observation in the present study was that zif268 expression was induced only in CA1 neurons and not in DG neurons during contextual memory recall. Both DG and CA1 neurons are known to support associative plasticity (Bliss and Collingridge 1993). Moreover, increased expression of zif268 can be induced in the DG after electrical stimulation of the perforant path (Cole et al., 1989; Wisden et al., 1990). However, increasing evidence suggests that CA1 neurons may be especially involved in the encoding and retrieval of contextual memories. These neurons have reciprocal connections with subcortical regions, including the B/LA, as well as cortical areas that are independent of the DG (van Groen and Wyss, 1990) and previous studies have also demonstrated CA1 neuronal activation despite inactivation of inputs from the DG (Mizumori et al., 1989). In addition, contextual conditioning has been shown to activate both the cAMPcalcium response element transcriptional pathway and expression of BDNF in CA1 neurons but not in the DG (Impey et al., 1998; Hall et al., 2000), and the IEG Arc is also expressed in CA1 neurons selectively after learning about a novel environment (Guzowski et al., 1999). Hippocampal CA1 neurons and their cortical and subcortical connections may therefore be particularly involved in both the acquisition and recall of contextual memories.

\section{Time-limited role of the hippocampus in memory retrieval}

Induction of zif 268 expression was seen in CA1 neurons after the retrieval of recent, but not older, contextual fear associations. This finding could not be explained by a decrease in memory for the fearful event itself, because animals showed equivalent levels of freezing to the conditioned context at both $24 \mathrm{hr}$ and $28 \mathrm{~d}$ after conditioning. This time-limited activation of zif268 expression in hippocampal CA1 neurons is consistent with results of animal and human studies demonstrating a temporal gradient in the impact of hippocampal lesions on fear memory recall, with sparing of older memories (Zola-Morgan et al., 1986; Kim and Fanselow, 1992; Rempel-Clower et al., 1996; Anagnostaras et al., 1999; Teng and Squire 1999). One explanation for this observation may be that memory traces become consolidated in extrahippocampal cortical areas over time with their recall becoming independent of the hippocampus (Bontempi et al., 1999; Teng and Squire, 1999 Alternatively, memories may become broadly distributed across multiple corticohippocampal circuits with increasing time from acquisition (Nadel and Moscovitch, 1997). Although the results of the present study more parsimoniously support the former view, an investigation of integrated cellular activation across all hippocampal regions, including the analysis of a number of genes, would be required to exclude the possibility that traces become more broadly distributed within the hippocampus over time or, indeed, that the memory remains within the hippocampus but no longer engages or requires further plasticity-related processes for its continued maintenance after retrieval.

\section{Amygdala activation during the retrieval of fear-associated memories}

The present results demonstrate increased zif268 expression within the amygdala during the retrieval of both cued and contextual fear memories and are therefore consistent with suggestions that the amygdala is a critical element of fear processing in general (Davis et al., 1994; Maren and Fanselow, 1996; Fanselow and LeDoux, 1999). Although a recent lesion study showed that the acquisition of cued freezing responses is dependent on the LA but not the B (Amorapanth et al., 2000), the present results demonstrate that the LA and $\mathrm{B}$ are recruited in concert during the retrieval of both cued and contextual aversive memories. The $\mathrm{CeN}$, which receives extensive connections from the LA and B (Pitkanen et al., 1997) and projects to brainstem regions, including those involved in the generation of freezing responses (Price and Amaral, 1981; LeDoux et al., 1988), was also found to be activated in both cued and contextual fear retrieval, consistent with the involvement of this nucleus in the generation of the freezing response (Davis, 1992; Maren and Fanselow, 1996; Fanselow and LeDoux, 1999). However the AB, which represents a major site of input of hippocampal afferents (Canteras and Swanson, 1992; Amaral and Witter, 1995; Maren and Fanselow, 1996) and has been implicated in contextual fear conditioning in some lesion studies (Majidishad et al., 1996), did not show increased zif 268 expression during the retrieval of contextual fear memories in the present study.

Overall our findings support a role for specific nuclei of the amygdala during the retrieval of fearful memories. This perhaps contrasting with suggestions that the amygdala may function only to reinforce the learning of emotionally salient associations in other brain regions (Cahill et al., 1999) but supporting previous studies demonstrating that post-training lesions (Lee et al., 1996; Maren et al., 1996) or pretraining, but not immediate posttraining, inactivation of the amygdala prevents conditioned freezing to either cued or contextual stimuli tested subsequently (Muller et al., 1997; Wilensky et al. 2000).

\section{Zif268 expression during memory retrieval}

Although there is an apparently close association of zif268 expression with hippocampal LTP, particularly in the DG (Cole et al., 1989; Wisden et al., 1990; Worley et al., 1993), studies have failed to find an association between zif 268 induction in the hippocampus and learning in hippocampal-dependent tasks (Wisden et al., 1990; Richter-Levin et al., 1998). Furthermore, we have recently shown that expression of zif 268 within the hippocampus and amygdala is not selectively induced during the acquisition of contextual fear conditioning (Hall et al., 2000). Increased zif268 expression in the LA after contextual conditioning compared with that measured in naive rats has been reported (Rosen et al., 1998), but, this induction of zif 268 may have been in part because of the nonspecific effects of the training procedure used, because the increased expression was not different from noncontextually conditioned rats that had experienced footshock presentations in the training context.

In contrast to the lack of correlation of zif268 expression with the acquisition of contextual fear conditioning, we demonstrate in the present study that zif268 expression is associated with memory retrieval. Synaptic plasticity during retrieval may contribute to the reorganization of hippocampal or amygdala memory traces over time. Importantly, a requirement for protein synthesis in the amygdala for the reconsolidation of cued fear memories after retrieval has been demonstrated, confirming that plasticity ac- 
companies the retrieval process (Nader et al., 2000). Although the molecular processes underlying this plasticity have not yet been elucidated, the present results suggest that zif268, which is selectively expressed during memory retrieval, may contribute to the encoding and recoding of the memory trace during retrieval.

\section{Conclusion}

This study has shown that the plasticity-associated IEG zif268 is expressed in specific neuronal populations in the hippocampus and amygdala during the retrieval of fear-associated memories. Expression of zif 268 was increased in hippocampal CA1 neurons after the retrieval of contextual, but not cued, fear memories. CA1 neurons were also found to express zif268 only during the retrieval of recently formed contextual memories, but not after the retrieval of older memories, suggesting that this cell population may form part of a corticohippocampal network mediating the temporal consolidation of contextual fear memories. In addition, neurons within the $\mathrm{B}, \mathrm{LA}$, and $\mathrm{CeN}$ nuclei of the amygdala, but not within the AB nucleus, showed increased zif268 expression during the retrieval of both cued and contextual fearassociated memories, supporting a role for these nuclei in the retrieval, as well as in the acquisition of fear-related memories. The selective expression of zif268 in neuronal populations required for fear memory retrieval suggests that this gene may play a role in the plastic reconsolidation of memories accompanying the retrieval process.

\section{REFERENCES}

Aggleton JP (1992) The functional effects of amygdala lesions in humans: a comparison with findings from monkeys. In: The amygdala: neurobiological aspects of emotion, memory, and mental dysfunction (Aggleton JP, ed), pp 485-504. New York: Wiley-Liss.

Amaral DG, Witter MP (1995) Hippocampal formation in the rat nervous system. In: The rat nervous system (Paxinos G, ed.), pp 443-494. London: Academic.

Amorapanth P, LeDoux JE, Nader K (2000) Differential lateral amygdala outputs mediate reactions and actions elicited by a fear-arousing stimulus. Nat Neurosci 3:74-79.

Anagnostaras SG, Maren S, Fanselow MS (1999) Temporally graded retrograde amnesia of contextual fear after hippocampal damage in rats: within-subjects examination. J Neurosci 19:1106-1114.

Bellgowan PSF, Helmstetter FJ (1995) Effects of muscimol applied to the dorsal hippocampus on the acquisition and expression of cued versus contextual fear conditioning. Soc Neurosci Abstr 21:478.

Bliss TVP, Collingridge GL (1993) A synaptic model of memory: longterm potentiation in the hippocampus. Nature 361:31-39.

Bontempi B, Laurent-Demir C, Destrade C, Jaffard R (1999) Timedependent reorganization of brain circuitry underlying long-term memory storage. Nature 400:671-675.

Cahill L, McGaugh JL (1998) Mechanisms of emotional arousal and lasting declarative memory. Trends Neurosci 21:294-299.

Cahill L, Weinberger NM, Roozendaal B, McGaugh JL (1999) Is the amygdala a locus of "conditioned fear"? Some questions and caveats. Neuron 23:227-228.

Canteras NS, Swanson LW (1992) Projections of the ventral subiculum to the amygdala, septum, and hypothalamus: a PHAL anterograde tract-tracing study in the rat. J Comp Neurol 324:180-194.

Cole AJ, Saffen DW, Baraban JM, Worley PF (1989) Rapid increase of an immediate early gene messenger RNA in hippocampal neurons by synaptic NMDA receptor activation. Nature 340:474-476.

Davis M (1992) The role of the amygdala in conditioned fear. In: The amygdala: neurobiological aspects of emotion, memory, and mental dysfunction. (Aggleton JP, ed), pp 255-306. New York: Wiley-Liss.

Davis M, Rainnie D, Cassell M (1994) Neurotransmission in the rat amygdala related to fear and anxiety. Trends Neurosci 17:208-214.

Fanselow MS (2000) Contextual fear, gestalt memories, and the hippocampus. Behav Brain Res 110:73-81.

Fanselow MS, LeDoux JE (1999) Why we think plasticity underlying Pavlovian fear conditioning occurs in the basolateral amygdala. Neuron 23:229-232.

Fendt M, Fanselow MS (1999) The neuroanatomical and neurochemical basis of conditioned fear. Neurosci Biobehav Rev 23:743-760.

Gewirtz JC, McNish KA, Davis M (2000) Is the hippocampus necessary for contextual fear conditioning? Behav Brain Res 110:83-95.

Gisquet-Verrier P, Dutrieux G, Richer P, Doyere V (1999) Effects of lesions to the hippocampus on contextual fear: evidence for a disruption of freezing and avoidance behavior but not context conditioning. Behav Neurosci 113:507-522.

Good M, Honey RC (1997) Dissociable effects of selective lesions to hippocampal subsystems on exploratory behavior, contextual learning, and spatial learning. Behav Neurosci 111:487-493.

Guzowski JF, McNaughton BL, Barnes CA, Worley PF (1999) Environment specific expression of the immediate early gene Arc in hippocampal neuronal ensembles. Nat Neurosci 2:1120-1124.

Hall J, Thomas KL, Everitt BJ (2000) Rapid and selective induction of BDNF expression in the hippocampus during contextual learning. Nat Neurosci 3:533-535.

Hamann SB, Ely TD, Grafton ST, Kilts CD (1999) Amygdala activity related to enhanced memory for pleasant and aversive stimuli. Nat Neurosci 2:289-293.

Holt W, Maren S (1999) Muscimol inactivation of the dorsal hippocampus impairs contextual retrieval of fear memory. J Neurosci 19:9054-9062.

Impey S, Smith DM, Obrietan K, Donahue R, Wade C, Storm DR (1998) Stimulation of cAMP response element (CRE)-mediated transcription during contextual learning. Nat Neurosci 1:595-601.

Killcross S, Robbins TW, Everitt BJ (1997) Different types of fearconditioned behaviour mediated by separate nuclei within amygdala. Nature 388:377-380.

Kim JJ, Fanselow MS (1992) Modality-specific retrograde amnesia of fear. Science 256:675-677.

Kim M, Davis M (1993) Lack of a temporal gradient of retrograde amnesia in rats with amygdala lesions assessed with the fear-potentiated startle paradigm. Behav Neurosci 107:1088-1092.

LeDoux JE, Iwata J, Cicchetti P, Reis DJ (1988) Different projections of the central amygdaloid nucleus mediate autonomic and behavioral correlates of conditioned fear. J Neurosci 8:2517-2529.

Lee Y, Walker D, Davis M (1996) Lack of a temporal gradient of retrograde amnesia following NMDA-induced lesions of the basolateral amygdala assessed with the fear-potentaiated startle paradigm. Behav Neurosci 110:836-839.

Liang KC, McGaugh JL, Martinez JL, Jensen RA, Vasquez BJ, Messing RB (1982) Post-training amygdaloid lesions impair retention of an inhibitory avoidance response. Behav Brain Res 4:237-249.

Majidishad P, Pelli DG, LeDoux JE (1996) Disruption of fear conditioning to contextual stimuli but not to tone by lesions of the accessory basal nucleus of the amygdala. Soc Neurosci Abstr 22:1116.

Maren S (1999) Neurotoxic basolateral amygdala lesions impair learning and memory but not the performance of conditional fear in rats. J Neurosci 19:8696-8703.

Maren S, Fanselow MS (1996) The amygdala and fear conditioning: has the nut been cracked? Neuron 16:237-240.

Maren S, Aharonov G, Fanselow MS (1996) Retrograde abolition of conditional fear after excitotoxic lesions in the basolateral amygdala of rats: absence of a temporal gradient. Behav Neurosci 110:718-726.

Maren S, Aharonov G, Fanselow MS (1997) Neurotoxic lesions of the dorsal hippocampus and Pavlovian fear conditioning in rats. Behav Brain Res 88:261-274.

Maren S, Anagnostaras SG, Fanselow MS (1998) The startled sea horse: is the hippocampus necessary for contextual fear conditioning. Trends Cogn Sci 2:39-44.

McGaugh JL, Cahill L, Roozendaal B (1996) Involvement of the amygdala in memory storage: interaction with other brain systems. Proc Natl Acad Sci USA 93:13508-13514.

McNish KA, Gewirtz JC, Davis M (1997) Evidence of contextual fear after lesions of the hippocampus: a disruption of freezing but not fear-potentiated startle. J Neurosci 17:9353-9360.

Milbrandt J (1987) A nerve growth factor-induced gene encodes a possible transcriptional regulatory factor. Science 238:797-799.

Mizumori SJ, McNaughton BL, Barnes CA, Fox KB (1989) Preserved spatial coding in hippocampal CA1 pyramidal cells during reversible suppression of CA3 output: evidence for pattern completion in hippocampus. J Neurosci 9:3915-3928.

Muller J, Corodimas KP, Fridel Z, LeDoux JE (1997) Functional inactivation of the lateral and basal nuclei of the amygdala by muscimol infusion prevents fear conditioning to an explicit conditioned stimulus and to contextual stimuli. Behav Neurosci 111:683-691.

Nadel L, Moscovitch M (1997) Memory consolidation, retrograde amnesia and the hippocampal complex. Curr Opin Neurobiol 7:217-227.

Nader K, Schafe GE, LeDoux J (2000) Fear memories require protein synthesis in the amygdala for reconsolidation after retrieval. Nature 406:722-726.

Phillips RG, LeDoux JE (1992) Differential contribution of amygdala and hippocampus to cued and contextual fear conditioning. Behav Neurosci 106:274-285.

Pitkanen A, Savander V, LeDoux JE (1997) Organization of intraamygdaloid circuitries in the rat: an emerging framework for understanding functions of the amygdala. Trends Neurosci 20:517-523.

Price JL, Amaral DG (1981) An autoradiographic study of the projec- 
tions of the central nucleus of the monkey amygdala. J Neurosci $1: 1242-1259$.

Rempel-Clower N, Zola SM, Squire LR, Amaral DG (1996) Three cases of enduring memory impairment after bilateral damage limited to the hippocampal formation. J Neurosci 16:5233-5255.

Richter-Levin G, Thomas KL, Hunt SP, Bliss TVP (1998) Dissociation between genes activated in long-term potentiation and in spatial learning in the rat. Neurosci Lett 251:41-44.

Rogan MT, LeDoux JE (1996) Emotion: systems, cells, synaptic plasticity. Cell 85:469-475.

Rosen JB, Fanselow MS, Young SL, Sitcoske M, Maren S (1998) Immediate-early gene expression in the amygdala following footshock stress and contextual fear conditioning. Brain Res 796:132-142.

Selden NRW, Everitt BJ, Jarrard LE, Robbins TW (1991) Complementary roles for the amygdala and hippocampus in aversive-conditioning to explicit and contextual cues. Neuroscience 42:335-350.

Teng E, Squire LR (1999) Memory for places learned long ago is intact after hippocampal damage. Nature 400:675-677.

van Groen T, Wyss JM (1990) Extrinsic projections from area CA1 of the rat hippocampus: olfactory, cortical, subcortical, and bilateral hippocampal formation projections. J Comp Neurol 302:515-528.
Vazdarjanova A, McGaugh JL (1998) Basolateral amygdala is not critical for cognitive memory of contextual fear conditioning. Proc Natl Acad Sci USA 95:15003-15007.

Wilensky AE, Schafe GE, LeDoux JE (2000) The amygdala modulates memory consolidation of fear motivated inhibitory avoidance learning but not classical fear conditioning, J Neurosci 20:7059-7066.

Wisden W, Morris BJ (1994) In situ hybridisation with synthetic oligonucleotide probes. In: In situ hybridisation protocols for the brain (Wisden W, Morris BJ, eds), pp 9-34. London: Academic.

Wisden W, Errington ML, Williams S, Dunnett SB, Waters C, Hitchcock D, Evan G, Bliss TVP, Hunt SP (1990) Differential expression of immediate early genes in the hippocampus and spinal cord. Neuron $4: 603-614$

Worley PF, Bhat RV, Baraban JM, Erickson CA, McNaughton BL, Barnes CA (1993) Threshold for synaptic activation of transcription factors in hippocampus: Correlation with long-term enhancement. J Neurosci 13:4776-4786.

Zola-Morgan S, Squire L, Amaral DG (1986) Human amnesia and the medial temporal region: enduring memory impairment following a bilateral lesion limited to field CA1 of the hippocampus. J Neurosci 6:2950-2967. 